\title{
Coloboma of macula
}

INSERM

\section{Source}

INSERM. (1999). Orphanet: an online rare disease and orphan drug data base. Coloboma of macula. ORPHA:98945

Coloboma of macula is a rare, non-syndromic developmental defect of the eye characterized by well-circumscribed, oval or rounded, usually unilateral, atrophic lesions of varying size presenting rudimentary or absent retina, choroid and sclera located at the macula leading to decreased vision and, on occasion, other symptoms (e.g. strabismus). It is usually isolated, but may also be associated with Down syndrome, skeletal or renal disorders. 